\title{
Vaginal bioelectrical impedance determines uterine receptivity in mice
}

DOI:

10.1093/humrep/dey313

10.1093/humrep/dey313

\section{Document Version}

Accepted author manuscript

Link to publication record in Manchester Research Explorer

\section{Citation for published version (APA):}

Nakamura, H., Hosono, T., Kumasawa, K., Jones, C. J. P., Aplin, J. D., \& Kimura, T. (2018). Vaginal bioelectrical impedance determines uterine receptivity in mice. Human reproduction (Oxford, England), 33(12), 2241-2248. https://doi.org/10.1093/humrep/dey313, https://doi.org/10.1093/humrep/dey313

\section{Published in:}

Human reproduction (Oxford, England)

\section{Citing this paper}

Please note that where the full-text provided on Manchester Research Explorer is the Author Accepted Manuscript or Proof version this may differ from the final Published version. If citing, it is advised that you check and use the publisher's definitive version.

\section{General rights}

Copyright and moral rights for the publications made accessible in the Research Explorer are retained by the authors and/or other copyright owners and it is a condition of accessing publications that users recognise and abide by the legal requirements associated with these rights.

\section{Takedown policy}

If you believe that this document breaches copyright please refer to the University of Manchester's Takedown Procedures [http://man.ac.uk/04Y6Bo] or contact uml.scholarlycommunications@manchester.ac.uk providing relevant details, so we can investigate your claim.

\section{OPEN ACCESS}


1 Vaginal bioelectrical impedance determines uterine receptivity in mice

2

$3 \quad$ Running title: Prospective evaluation of uterine receptivity

4

5 Hitomi Nakamura $(\mathrm{HN})^{1 *}$, Takayoshi Hosono $(\mathrm{TH})^{2}$, Keiichi Kumasawa $(\mathrm{KK})^{1}$,

6 Carolyn J.P. Jones (CJPJ) ${ }^{3,4}$, John D Aplin (JDA) ${ }^{3,4}$, Tadashi Kimura (TK) ${ }^{1}$

7

$8{ }^{1}$ Department of Obstetrics and Gynaecology, Osaka University Graduate School of 9 Medicine, 2-2 Yamadaoka, Suita, Osaka 5650871, Japan

10

$11{ }^{2}$ Graduate School of Biomedical Engineering, Osaka Electro-Communication

${ }^{4}$ Maternal and Fetal Health Research Centre, St. Mary’s Hospital, Central Manchester University Hospitals NHS Foundation Trust, Manchester Academic Health Sciences

Centre, Manchester, M13 9WL, UK

* Corresponding author

E-mail: hitomi@gyne.med.osaka-u.ac.jp (HN) 
Abstract

\section{STUDY QUESTION:}

Can vaginal bioelectrical impedance (VZ) electrophysiologically determine alterations of the endometrium in preparation for implantation?

\section{SUMMARY ANSWER:}

VZ can electrophysiologically detect the sulfation and sialylation changes in the uterine glycocalyx in preparation for implantation.

\section{WHAT IS KNOWN ALREADY:}

Uterine receptivity is associated with various glycosylation changes that affect negative charge density at the luminal epithelial cell surface. VZ has been used to monitor the oestrous cycle.

\section{STUDY DESIGN, SIZE, DURATION:}

Pathogen-free Jcl:ICR mice, aged 8-10 weeks, were used in this study. We conducted the following three steps to test our hypothesis that VZ may be used to determine uterine receptivity. First, to investigate whether VZ could determine alteration of sulfation and sialylation in the uterine glycocalyx, VZ was measured in mice with induced artificial sulfation and sialylation changes in the uterine glycocalyx (Galactose-3-O-sulfotransferase $2(\mathrm{GP} 3 \mathrm{ST})+\alpha(1,3 / 1,4)$ fucosyl-transferase gene (FucT-III)-transferred group $(\mathrm{n}=15)$ and in LacZ (encoding for $\beta$-galactosidase) -transferred mice as a control group $(n=12))$. Second, to investigate whether VZ could determine alterations of the endometrium in preparation for implantation, we measured 
VZ during the early stage of pregnancy $(\mathrm{n}=12$ each). Third, to investigate whether VZ could be used to evaluate uterine receptivity prospectively, VZ was measured in an implantation failure model mice. In 21 mice, local and transient suppression of signal transducer and activator of transcription-3 (Stat3) in the uterus were evaluated 1 day before implantation began, and 23 scramble decoy-transferred mice were used as a control group.

\section{PARTICIPANTS/MATERIALS, SETTING, METHODS:}

The VZ was measured at a frequency of $1 \mathrm{kHz}$ in Jcl:ICR mice. Data were analyzed using the Kruskal-Wallis test with Dunn's multiple comparisons, or the Student's $t$-test or Wilcoxon's rank-sum test with the Shapiro-Wilk normality test. The values of VZ were analysed using receiver operating characteristic (ROC) curve analysis to identify the optimal cut-off point to determine if this parameter predicted non-pregnancy.

\section{MAIN RESULTS AND THE ROLE OF CHANCE:}

Sulfation and sialylation changes induced in the luminal epithelial glycocalyx decreased the value of VZ. VZ showed a significant daily decrease during the early stage of pregnancy (day 1.5 versus 2.5 p.c.: $P<0.005$; Student's t-test, day 2.5 versus 3.5 p.c.: $P$ $<0.001$; Wilcoxon's rank-sum test, day 3.5 versus 4.5 p.c.: $P<0.005$; Student's t-test, day 4.5 versus 5.5 p.c.: $P<0.05$; Student's t-test). One day before implantation began, VZ in the implantation failure model mice was significantly higher than in the control mice ( $P<0.001$, Wilcoxon's rank-sum test). The ROC curve analysis of $\mathrm{VZ}$ as a predictor of non-conception showed areas under the ROC curve of 0.91 (95\% CI: 0.83 to 0.99$)$. 


\section{LIMITATIONS AND REASONS FOR CAUTION:}

Although it is influenced by surface charge in the uterine epithelium, the mechanism whereby VZ changes during early pregnancy is still unexplained.

\section{WIDER IMPLICATIONS OF THE FINDINGS:}

Local bioelectrical impedance may help to prospectively evaluate uterine receptivity in women. Including the measurement of local bioelectrical impedance as part of a frozen-thawed embryo transfer strategy may improve the efficiency of ART.

\section{STUDY FUNDING/COMPETING INTEREST(S):}

This work was supported in part by the Japan Society for the Promotion of Science JSPS KAKENHI Grant (No. 19390429, 21390453, 16K11086, 16K11087) from the Ministry of Education, Science, and Culture of Japan (Tokyo, Japan) and SUZUKEN MEMORIAL FOUNDATION (Nagoya, Japan). The authors declare that they have no conflict of interest.

\section{Key words}

Implantation, vaginal bioelectrical impedance, uterine receptivity, infertility, glycocalyx 


\section{Introduction}

Implantation failure has long been considered a major problem in infertility treatment. To improve infertility treatment, more accurate evaluation of uterine receptivity is needed. Uterine receptivity is probably not the same in every menstrual cycle because the maximum efficiency of human reproduction is approximately $30 \%$ per cycle (Wilcox, et al., 1988). Ideally, uterine receptivity should be evaluated prospectively for each menstrual cycle.

The association of receptivity with glycosylation changes, including changes in the composition of glycoproteins, proteoglycans, and glycolipids in the endometrial epithelium in mouse (Morris, et al., 1988), rabbit (Anderson, et al., 1986, Zhu, et al., 1992 ), and a variety of species including human (Aplin and Jones, 2012, Aplin, et al., 2001, Zhu, et al., 1990), and the secretion profile of glycoproteins and proteoglycans in luminal fluid in mouse (Morris et al., 1988) and human (Bell, et al., 1986) has previously been reported. Implantation has been suggested to begin with binding between L-selectin on trophoblasts and oligosaccharide-based ligands, including 6-sulfo $\operatorname{sLe}^{\mathrm{x}}\left(\mathrm{Sia} \alpha 2 \rightarrow 3 \mathrm{Gal} \beta 1 \rightarrow 4[\mathrm{Fuc} \alpha 1 \rightarrow 3]\left[\mathrm{SO}_{3} \rightarrow 6\right] \mathrm{GlcNAc}\right)$ on the uterine endometrial epithelial cells (Fazleabas and Kim, 2003, Genbacev, et al., 2003). The alterations of the glycocalyx throughout the whole uterus involve shifts in sialylation and sulfation.

However, it is unknown if these alterations are detectable in the vagina using electrical impedance.

Bioelectrical impedance is the measurement of the circuit that is opposite to an alternating current when a voltage is applied (Kyle, et al., 2004). Vaginal bioelectrical impedance (VZ) has been applied to detect oestrus and ovulation time in a wide range of mammals including cattle, sheep, goats, horses, pigs and human (Rezac, 2008). The 
most popular application is to detect pro-oestrus in rats (Bartos, 1977, Koto, et al., 1987, Koto, et al., 1987, Ramos, et al., 2001, Singletary, et al., 2005). If the measurement of $\mathrm{VZ}$ can determine alterations of the endometrium to prepare it for implantation, can this parameter be used to evaluate receptivity?

In a previous study, we established an implantation failure mouse model using transient and local suppression of a signal transducer and activator of transcription 3 (Stat3) activity, using a Stat3 decoy that was transferred into the uterine cavity during implantation (Nakamura, et al., 2006). The Stat3 decoy transfer suppressed approximately $50 \%$ of the Stat 3 activity in the uterus during the implantation period and it resulted in implantation failure that was caused by the suppression of decidualisation but with normal progesterone levels. In the present study we assessed VZ using this previous implantation failure mouse model to investigate whether the measurement of VZ might help to identify the receptivity status of the uterus. 


\section{Materials and Methods}

\section{Ethical approval}

This study was approved by the animal ethics committees of Osaka University Graduate School of Medicine and Osaka Electro-Communication University. All experiments were performed according to the appropriate guidelines for animal use that were approved by the Institutional Animal Care and Use Committee (Permit Number 19-037-3, 24-001-018, and Seirinnin08-013) and the Genetic Modification Experiments Safety Committee at Osaka University (Permit Number 3333).

\section{Animals}

Specific pathogen-free Jcl:ICR mice that were purchased from a commercial breeder (SLC, Shizuoka, Japan) were used in this study. The animals were maintained under controlled conditions (temperature: $23.0 \pm 1.5{ }^{\circ} \mathrm{C}$; relative humidity: $45 \pm 15 \%$ ). The light cycle was 12/12 h; lights were turned off at 8:00 pm and turned on at 8:00 am. The mice were acclimatised for at least 1 week before the experiments were begun. Virgin female Jcl:ICR mice, aged 8-10 weeks, were examined using vaginal smears to determine their sexual phases, as described in a previous study (Byers, et al., 2012). Female mice in pro-oestrus and oestrus were mated with male Jcl:ICR mice. The morning on which vaginal plugging was first observed was designated as day 0.5 post-coitus (p.c.).

\section{DNA preparation}


page. 8 / 31

A $\beta$ Gal 3-O-sulfotransferase (GP3ST)-expressing plasmid pcXN2-GP3ST and an $\alpha(1,3 / 1,4)$ fucosyltransferase (FucT-III)-expressing plasmid pcDNA-FucT-III (Ikeda, et al., 2001) were kindly provided by Professor Koichi Honke (Department of Biochemistry, Kochi University Medical School, Kochi, Japan). The GP3ST cDNA was introduced into the pcDNA3 expression vector (cytomegalovirus promoter driven; Invitrogen, San Diego, CA, USA) at the EcoRI-XhoI sites. Plasmid DNA was purified using a Qiagen ${ }^{\circledR}$ EndoFree plasmid purification kit (Tokyo, Japan). Control plasmid DNA transfers were performed using pcDNA3-LacZ plasmid DNA (Nakamura, et al., 2003). A Stat-3 decoy (5'-CCTTCCGGGAATTCCTTCCGGGAATTC-3'; underlines indicate consensus element) and a scramble decoy (5'-AGTCCATTCGGCAGGCCTCTGCTCTAT-3') were prepared as described previously (Nakamura, et al., 2006).

\section{Gene transfer}

Four hundred micrograms each of GP3ST and FucT-III-expressing plasmid DNA $(n=15)$ or $800 \mu \mathrm{g}$ of LacZ-expressing plasmid DNA as a control $(\mathrm{n}=12)$ were transferred into murine uteri at pro-oestrus with a haemagglutinating virus of Japan envelope (HVJ-E) vector (GenomONE-NEO®, Ishihara Sangyo Co., Ltd., Osaka, Japan), a nonproliferative and noninfectious vesicle about $300 \mathrm{~nm}$ in diameter purified after complete inactivation of Sendai virus genomic RNA. Double-stranded decoy 
oligodeoxynucleotides were transferred into the murine uteri (Stat3 decoy: $\mathrm{n}=21$, scramble decoy: $\mathrm{n}=23$ ) with the HVJ-E vector on day 1.5 p.c. as described previously (Nakamura, et al., 2003).

\section{Measurement of VZ}

The mice were anaesthetised with isoflurane (Forane ${ }^{\circledR}$, Abbott Japan Co., Ltd., Tokyo, Japan), which was delivered via a face mask at 5\% during induction and at $1 \%-2 \%$ during measurement. The $\mathrm{VZ}$ was measured at a frequency of $1 \mathrm{kHz}$ using a rat vaginal impedance checker (Model MK-11, Muromachi Kikai Co., Ltd., Tokyo, Japan) and mouse probe (MP-35, Muromachi Kikai Co., Ltd.) (Fig. 1) during the oestrous cycle and the early stage of pregnancy. Our preliminary study showed that when the distance between the probe sensor and the ostium of the uterus, which is the cephalic end of the vagina, was more than $7 \mathrm{~mm}$, the variability of the individual VZ value became greater (Supplementary Fig. S1). The probe was inserted into the vagina until it touched the ostium and then the probe was removed. The VZ was measured at 0-7 mm from the ostium. External contact pressure is known to affect the body-electrode interface impedance, as well as the range of bioelectrical impedance (Minczak, 2010).

To keep the same measurement conditions, we fixed the probe using a small animal stereotaxic instrument. During the oestrous cycle, vaginal smears were collected immediately after measurement of VZ $(n=63)$.

\section{Histological analysis}

Uterine tissues were removed and formalin-fixed. The 4- $\mu \mathrm{m}$ of paraffin-embedded tissue sections were used for histological analysis. 


\section{Lectin staining}

Paraffin-embedded sections were deparaffinised and then rinsed in distilled water. To eliminate the endogenous peroxidase activity, sections were incubated with $3 \%$ hydrogen peroxide for 20 min at room temperature. After rinsing in water and washing twice for $5 \mathrm{~min}$ in $0.05 \mathrm{M}$ Tris-buffered saline (TBS, $\mathrm{pH}$ 7.6), sections were incubated in $10 \mu \mathrm{g} / \mathrm{ml}$ of MAM (Maackia amurensis mitogen, J-Chemical, Inc., Tokyo, Japan) biotinylated lectin in $0.05 \mathrm{M}$ TBS containing $1 \mathrm{mM}$ calcium chloride at room temperature for 1 hour. Washing for $15 \mathrm{~min}$ in $0.05 \mathrm{M}$ TBS with $1 \mathrm{mM}$ calcium chloride (three changes) was followed by incubation with streptavidin-biotin-peroxidase complex (Histofine ${ }^{\circledR}$, Nichirei, Tokyo, Japan) for $30 \mathrm{~min}$ at room temperature. The lectin binding sites were visualized with 3, 3'-diaminobenzidine tetrahydrochloride (DAB). Hematoxylin was used for counterstaining.

To remove sialic acids from oligosaccharides, the sections were treated for 1.5 hours at $37^{\circ} \mathrm{C}$ with 0.1 units/ml neuraminidase from Vibrio cholerae (Roche, Tokyo, Japan) in $0.05 \mathrm{M}$ sodium acetate buffer ( $\mathrm{pH}$ 5.5) containing $4 \mathrm{mM}$ calcium chloride before the treatment with hydrogen peroxide as described above.

\section{Alcian blue staining}

The presence of sulfated and carboxylated mucins as well as proteoglycans and hyaluronic acid can be demonstrated by staining with alcian blue. Saponification after methylation reverses the staining for the carboxylated mucins and hyaluronic acid, but not for sulfated mucins and/or sulfated proteoglycans (Myers, et al., 2008).

Paraffin-embedded, deparaffinised sections were processed using an alcian blue staining 
kit (Muto pure Chemicals Co., Ltd., Tokyo, Japan) following the manufacturer's protocol. To indentify carboxyl or sulfate acid groups in mucins, the combined methylation and saponification treatments were performed before staining with alcian blue, as previously reported (Spicer and Lillie, 1959). In brief, for the methylation procedure, the sections were incubated in the acid methanol solution $(0.1 \mathrm{~N}$ hydrochloric acid in absolute methanol) at $60{ }^{\circ} \mathrm{C}$ for 5 hours. After washing in running tap water for $5 \mathrm{~min}$, the sections were incubated with saponification solution ( $1 \mathrm{~g}$ of potassium hydroxide in $100 \mathrm{ml}$ of $70 \%$ ethanol) at room temperature for $30 \mathrm{~min}$. Kernechtrot (Muto pure Chemicals Co., Ltd., Tokyo, Japan) was used for counterstaining.

\section{Analysis of implantation}

We administered an injection of $0.5 \%$ Evans Blue i.v. to day 5.0 p.c. pregnant animals, 15 min prior to euthanising them to visualise the implantation sites (Huet and Dey, 1987).

\section{Statistical analyses}

The experimental results are expressed as the mean $\pm \mathrm{SD}$. The data were analysed using SigmaPlot ${ }^{\circledR}$ software 10.01 (Systat Software, Inc., San Jose, CA, USA). Data were analysed using the Kruskal-Wallis test with Dunn's multiple comparisons, or the Student's $t$-test or Wilcoxon's rank-sum test with the Shapiro-Wilk normality test. Differences with a $P$-value of less than 0.05 were considered significant. The values of $\mathrm{VZ}$ were analysed using a receiver operating characteristic (ROC) curve analysis to 
page. 12 / 31

243

identify the optimal cut-off point to determine if this parameter was predictive of

244 non-pregnancy.

245 
Results

247

$V Z$ detects the oestrous cycle in mice

The measurement system which we used in this study showed that the VZ during oestrus $(3.78 \pm 2.24 \mathrm{k} \Omega ; \mathrm{n}=20)$ was significantly higher (Kruskal-Wallis test with Dunn's multiple comparisons) than in other stages of the cycle $(1.69 \pm 1.63 \mathrm{k} \Omega$ in pro-oestrus; $\mathrm{n}=18,1.11 \pm 0.68 \mathrm{k} \Omega$ in met-oestrus; $\mathrm{n}=12$, and $0.97 \pm 0.32 \mathrm{k} \Omega ; \mathrm{n}=13$ in di-oestrus phases) (Fig. 2).

\section{$V Z$ detects alteration of the glycocalyx}

The staining for alcian blue (Fig. 3B) and MAM (specified to Siaa2-3Gal) lectin (Fig. 3F) was seen in luminal and glandular epithelium in the GP3ST+

FucT-III-transferred group, while there was no staining for either alcian blue or MAM in luminal epithelium in the control group 24 hours after gene transfection. (Fig. 3A and E). Consistent with gene transfer being restricted to luminal epithelium, MAM lectin staining in glandular epithelium was the same in the control and transfected tissues (Fig. 3E). After methylation, staining for alcian blue was not observed in either luminal or glandular epithelium (Fig. 3C) and saponification failed to reverse this (Fig. 3D). Pre-treatment with neuraminidase attenuated the MAM lectin staining in both luminal and glandular epithelium (Fig. 3G).

Twenty-four hours after gene transfection, the GP3ST+ FucT-III-transferred group showed a significantly decreased $\mathrm{VZ}(0.73 \pm 0.06 \mathrm{k} \Omega, P=0.010$, Wilcoxon’s rank-sum test) compared with that in the control group $(1.08 \pm 0.11 \mathrm{k} \Omega)$ (Fig. 4). This 
result suggests that $\mathrm{VZ}$ can detect the sulfation and sialylation changes in the uterine glycocalyx.

\section{$V Z$ during the early stages of pregnancy in mice}

Pregnancy is established after the uterine endometrium goes through several complex orchestrated changes during the implantation period after ovulation. We investigated whether VZ could be used to detect pre-implantation changes.

The VZ declined monotonically with days post-coitum (Fig. 5) and was significantly lower on day 5.5 than that on the previous day $(1.83 \pm 0.10 \mathrm{k} \Omega$ on day 1.5 p.c. versus $1.21 \pm 0.03 \mathrm{k} \Omega$ on day 2.5 p.c., $P<0.001$; Student's $t$-test, on day 2.5 p.c. versus $0.88 \pm 0.03 \mathrm{k} \Omega$ on day 3.5 p.c., $P<0.001$; Wilcoxon rank-sum test, on day 3.5 p.c. versus $0.76 \pm 0.02 \mathrm{k} \Omega$ on day 4.5 p.c., $P=0.004$; Student's $t$-test, on day 4.5 p.c. versus $0.68 \pm 0.02 \mathrm{k} \Omega$ on day 5.5 p.c., $P=0.029$; Student's $t$-test). The measurement of VZ did not suppress pregnancy, and all pups were delivered between day 18.5 and 19.5 p.c.

Alteration of sulfation and sialylation in the uterine glycocalyx after the local suppression of Stat3 activity in uterus in mice

It was found that on day 5.0 p.c., $75 \%$ of mice (6/8) did not exhibit implantation sites that were detected using Evans Blue. Only two of the mice had implantation sites on one side, while implantation sites were evident in all mice on which the scramble decoy transfer was performed (8/8) (Supplementary Fig. S2A). To assess whether the transient and local suppression of Stat3 activity altered the sulfation and sialylation of the uterine glycocalyx, alcian blue staining and MAM lectin staining were performed 
using uterine tissue 24 hours after the gene transfection (day 2.5 p.c.). Alcian blue staining was observed in luminal and glandular epithelium and stromal cells in the control group (Fig. 6A and C), whilst there was much less staining in the Stat3 decoy transferred group (Fig. 6B and D). There was no difference in MAM lectin staining between these two groups (Fig. 6E and F). Methylation pretreatment attenuated alcian blue staining (Supplementary Fig. S2B) and the saponification pretreatment did not reverse the effect of methylation (Supplementary Fig. S2C). Pretreatment with neuraminidase attenuated the MAM lectin staining (Supplementary Fig. S2D, and E).

\section{VZ can predict pregnancy}

On day 2.5 p.c., 1 day before implantation, mice with a Stat 3 decoy showed a significantly higher $\mathrm{VZ}(1.54 \pm 0.41 \mathrm{k} \Omega)$ than the scramble decoy-transferred mice $(1.05 \pm 0.20 \mathrm{k} \Omega, P<0.001$, Wilcoxon's rank-sum test) (Fig. 7A) and naive mice (data not shown). There was no significant difference between the naive and scramble decoy-transferred groups (data not shown).

After observing the pregnancy outcome, we assessed the negative predictive value of $\mathrm{VZ}$ regarding conception. The ROC curve analysis of $\mathrm{VZ}$ as a predictor of non-conception showed areas under the ROC curve of 0.91 (95\% CI, 0.83 to 0.99 ) (Fig. 7B). The optimal cut-off value of $\mathrm{VZ}$ at $1.25 \mathrm{k} \Omega$ had a sensitivity of $82.6 \%$ and a specificity (non-conception) of $76.2 \%$. 


\section{Discussion}

The active and passive electrical properties of biological systems have been applied for clinical purposes for a long time. An active response occurs when biological tissues provoke electricity from ionic activities inside cells, such as electrocardiography signals from the heart and electroencephalography signals from the brain. Passive responses occur when biological tissues are simulated through an external electrical current source, such as during analysis of bioelectrical impedance (Kyle, et al., 2004). Analysis of bioelectrical impedance has been applied for various purposes including clinical monitoring of pulmonary, cardiovascular, circulatory, and renal systems (Khalil, et al., 2014). VZ has been applied to detect oestrus and ovulation time in animals and humans since the 1970s (Rezac, 2008) and previous authors have also found that VZ is higher at oestrus than at other stages of the cycle (Agrawal, et al., 2009, Weixelbaumer, et al., 2014, Wood, et al., 2007).

Various glycosylation changes including sulfation and sialylation occur in the endometrium during the preparation for implantation. Local $\mathrm{pH}$ changes arising from the altered abundance of strong and weak anions in the uterine glycocalyx in vivo might be detected by VZ. A system for remodelling the 3'-sulfo-Le ${ }^{\mathrm{a}}$ and 3 '-sulfo-Le ${ }^{\mathrm{x}}$ epitopes (Ikeda, et al., 2001) was used to investigate this. The local in vivo gene transfection system for the uterus using the HVJ-E vector showed peak expression of the introduced gene 24 hours after transfection. The expression of introduced genes has been shown to be mainly in the luminal and glandular epithelium when the cytomegalovirus promoter-driven plasmid vector is used (Nakamura, et al., 2003). 
As an application of bioelectrical impedance analysis, the analysis of body compartments, such as fat-free mass, total body water, extracellular and intracellular water and body cell mass, is much more popular than the analysis of VZ. The instruments for the body compartments analysis use single (generally at $50 \mathrm{kHz}$ ) or multi $(0,1,5,50,100,200$ to $500 \mathrm{kHz})$ frequency methods (Kyle, et al., 2004). When bioelectrical impedance is analysed at low frequency, the current passes through the extracellular fluid because the current does not penetrate the cell membrane, which acts as an insulator. On the other hand, at very high frequency, both intra- and extra-cellular fluid are reflected in the measurement value (Kyle, et al., 2004). The instrument used in the present study uses a single frequency at $1 \mathrm{kHz}$. It does not reflect the intracellular fluid condition but it does reflect that of the extracellular fluid. Alterations of sulfation and sialylation are the most common conditions that affect the value of bioelectrical impedance (Pethig and Kell, 1987). The artificial sulfation and sialylation changes in the glycocalyx of luminal uterine epithelium induced here decreased the value of VZ. Though it has been suggested that VZ might be influenced by alterations in the circulating levels of oestrogen and progesterone (Rezac, 2008) there is no correlation between the circulating levels of oestrogen and progesterone and VZ in rats (Singletary, et al., 2005), and circulating oestrogen and progesterone could only affect the value of VZ indirectly. During the preparation for implantation, various changes involving a wide range of molecules, including those comprising the glycocalyx, occur in the uterine endometrium (Aplin, et al., 2001, Cha, et al., 2012). However, these mechanisms are poorly understood. This study shows that VZ determines the alteration of the endometrium in preparation for implantation. However, mechanisms of direct molecular regulation of $\mathrm{VZ}$ are unknown and need to be evaluated in further studies. 
Our previous study showed that the local and transient uterine gene transfection of

Stat 3 decoy on day 1.5 p.c. suppressed approximately $50 \%$ of Stat 3 activity in the uterus

on day 5.0 p.c., resulting in $<30 \%$ implantation (Nakamura, et al., 2006). The significant increase in VZ in this implantation failure model group could be related to the diminution of sulphated uterine glycocalyx in luminal endometrium, but not to progesterone because the implantation failure model mice used in this study showed normal serum progesterone levels (Nakamura, et al., 2006). Women with unexplained infertility also show normal serum progesterone levels and implantation failure can be an important cause of infertility. It has been reported that there was a significantly lower level of phosphorylated STAT3 in uterine endometrium during the mid-luteal phase in women with recurrent/repeated implantation failure (Choi, et al., 2016, Dimitriadis, et al., 2007) and in repeated implantation failure in women with dormant genital tuberculosis (Subramani, et al., 2016) compared to the fertile control groups.

It is still unclear whether alteration of sulfation is directly related to uterine receptivity in women. However, the alteration of sulfation in the uterine glycocalyx may be essential to prepare for implantation in women. During the menstrual cycle, the amount of sulfoglycolipid is changed (Kamei, et al., 1997, Kubushiro, et al., 1989). The expression of sulfoglycolipid is increased due to increased activation of sulfotransferase, which regulates the synthesis of sulfoglycolipid, and a concurrent reduction of arylsulfatase A activity, which regulates the degradation of sulfoglycolipid in human uterine endometrium during the luteal phase (Kamei, et al., 1997).

Although we have to assess the optimum VZ cut-off value for predicting non-conception for women, measurement of VZ may also help to prospectively evaluate uterine receptivity in women. The technique of freezing and thawing embryos is already 
page. 19 / 31

384 well established and has been used in ART treatment worldwide. Measuring VZ

385 combined with a frozen-thawed embryo transfer strategy may improve the efficiency of

$386 \quad$ ART treatment. 
We thank Professor Eiji Miyoshi (Osaka University) for critical advice about the glycocalyx, and Dr. Kenji Minato, Mr. Atsushi Ito, Ms. Manami Yamamoto, Mr. Ryota Kojima (Osaka Electro-Communication University), Ms Satomi Okamoto, and Ms Eriko Kamata (Osaka University) for their technical assistance.

393

394

Authors' roles

396 and T.H.: data analysis and interpretation; H.N., J.D.A., and C.J.P.J.: evaluation of sulfation and sialylation; K.K.: statistical analysis; H.N., J.D.A., C.J.P.J., K.K., and T.K.: writing the manuscript. All authors read and approved the final manuscript. 
page. 21 / 31

$400 \quad$ Funding

401 Part by the Japan Society for the Promotion of Science JSPS KAKENHI Grant (Nos.

$40219390429,21390453,16 \mathrm{~K} 11086$ and 16K11087) from the Ministry of Education,

403 Science, and Culture of Japan (Tokyo, Japan) and Suzuken Memorial Foundation

404 (Nagoya, Japan).

405 
page. 22 / 31

\section{Conflict of interest}

407 The authors declare that they have no conflicts of interest.

408 


\section{References}

Agrawal V, Jaiswal MK, Chaturvedi MM, Tiwari DC, Jaiswal YK. Lipopolysaccharide alters the vaginal electrical resistance in cycling and pregnant mice. Am J Reprod Immunol 2009;61: 158-166.

Anderson TL, Olson GE, Hoffman LH. Stage-specific alterations in the apical membrane glycoproteins of endometrial epithelial cells related to implantation in rabbits. Biol Reprod 1986;34: 701-720.

Aplin JD, Jones CJ. Fucose, placental evolution and the glycocode. Glycobiology 2012;22: 470-478.

Aplin JD, Meseguer M, Simon C, Ortiz ME, Croxatto H, Jones CJ. MUC1, glycans and the cell-surface barrier to embryo implantation. Biochem Soc Trans 2001;29: 153-156.

Bartos L. Vaginal impedance measurement used for mating in the rat. Lab Anim 1977;11: 53-55.

Bell SC, Patel SR, Kirwan PH, Drife JO. Protein synthesis and secretion by the human endometrium during the menstrual cycle and the effect of progesterone in vitro. J Reprod Fertil 1986;77: 221-231.

Byers SL, Wiles MV, Dunn SL, Taft RA. Mouse estrous cycle identification tool and images. PLoS One 2012;7: e35538.

Cha J, Sun X, Dey SK. Mechanisms of implantation: strategies for successful pregnancy. Nat Med 2012;18: 1754-1767.

Choi Y, Kim HR, Lim EJ, Park M, Yoon JA, Kim YS, Kim EK, Shin JE, Kim JH, Kwon $\mathrm{H}$ et al. Integrative Analyses of Uterine Transcriptome and MicroRNAome Reveal Compromised LIF-STAT3 Signaling and Progesterone 
Response in the Endometrium of Patients with Recurrent/Repeated Implantation Failure (RIF). PLoS One 2016;11: e0157696.

Dimitriadis E, Sharkey AM, Tan YL, Salamonsen LA, Sherwin JR. Immunolocalisation of phosphorylated STAT3, interleukin 11 and leukaemia inhibitory factor in endometrium of women with unexplained infertility during the implantation window. Reprod Biol Endocrinol 2007;5: 44.

Fazleabas AT, Kim JJ. Development. What makes an embryo stick? Science 2003;299: 355-356.

Genbacev OD, Prakobphol A, Foulk RA, Krtolica AR, Ilic D, Singer MS, Yang ZQ, Kiessling LL, Rosen SD, Fisher SJ. Trophoblast L-selectin-mediated adhesion at the maternal-fetal interface. Science 2003;299: 405-408.

Huet YM, Dey SK. Role of early and late oestrogenic effects on implantation in the mouse. J Reprod Fertil 1987;81: 453-458.

Ikeda N, Eguchi H, Nishihara S, Narimatsu H, Kannagi R, Irimura T, Ohta M, Matsuda H, Taniguchi N, Honke K. A remodeling system of the 3'-sulfo-Lewis a and 3'-sulfo-Lewis x epitopes. J Biol Chem 2001;276: 38588-38594.

Kamei K, Kubushiro K, Fujii T, Tsukazaki K, Nozawa S, Iwamori M. Menstrual cycle-associated regulation of anabolic and catabolic enzymes causes luteal phase-characteristic expression of sulfatide in human endometrium. Am J Obstet Gynecol 1997;176: 142-149.

Khalil SF, Mohktar MS, Ibrahim F. The theory and fundamentals of bioimpedance analysis in clinical status monitoring and diagnosis of diseases. Sensors (Basel) 2014;14: 10895-10928. 
Koto M, Miwa M, Togashi M, Tsuji K, Okamoto M, Adachi J. [A method for detecting the optimum day for mating during the 4-day estrous cycle in the rat; measuring the value of electrical impedance of the vagina]. Jikken Dobutsu 1987;36: 195-198.

Koto M, Miwa M, Tsuji K, Okamoto M, Adachi J. [Change in the electrical impedance caused by cornification of the epithelial cell layer of the vaginal mucosa in the rat]. Jikken Dobutsu 1987;36: 151-156.

Kubushiro K, Kojima K, Mikami M, Nozawa S, Iizuka R, Iwamori M, Nagai Y. Menstrual cycle-associated alteration of sulfogalactosylceramide in human uterine endometrium: possible induction of glycolipid sulfation by sex steroid hormones. Arch Biochem Biophys 1989;268: 129-136.

Kyle UG, Bosaeus I, De Lorenzo AD, Deurenberg P, Elia M, Gomez JM, Heitmann BL, Kent-Smith L, Melchior JC, Pirlich M et al. Bioelectrical impedance analysis--part I: review of principles and methods. Clin Nutr 2004;23: 1226-1243.

Minczak BM. Chapter 12, Defibrillation and Cardioversion. In Roberts JR and Hedges JR (eds) Clinical Procedures in Emergency Medicine. 2010. Saunders Elsevier, Philadelphia.

Morris JE, Potter SW, Gaza-Bulseco G. Estradiol-stimulated turnover of heparan sulfate proteoglycan in mouse uterine epithelium. J Biol Chem 1988;263: 4712-4718.

Myers RB, Fredenburgh JL, Grizzle WE. Carbohydrates. In Bancroft JD (ed) Theory and Practice of Histological Techniques. 2008. Elsevier Health Sciences, pp. 161-186. 
Nakamura H, Kimura T, Ikegami H, Ogita K, Koyama S, Shimoya K, Tsujie T, Koyama M, Kaneda Y, Murata Y. Highly efficient and minimally invasive in-vivo gene transfer to the mouse uterus using haemagglutinating virus of Japan (HVJ) envelope vector. Mol Hum Reprod 2003;9: 603-609.

Nakamura H, Kimura T, Koyama S, Ogita K, Tsutsui T, Shimoya K, Taniguchi T, Koyama M, Kaneda Y, Murata Y. Mouse model of human infertility: transient and local inhibition of endometrial STAT-3 activation results in implantation failure. FEBS Lett 2006;580: 2717-2722.

Pethig R, Kell DB. The passive electrical properties of biological systems: their significance in physiology, biophysics and biotechnology. Phys Med Biol 1987;32: 933-970.

Ramos SD, Lee JM, Peuler JD. An inexpensive meter to measure differences in electrical resistance in the rat vagina during the ovarian cycle. J Appl Physiol (1985) 2001;91: 667-670.

Rezac P. Potential applications of electrical impedance techniques in female mammalian reproduction. Theriogenology 2008;70: 1-14.

Singletary SJ, Kirsch AJ, Watson J, Karim BO, Huso DL, Hurn PD, Murphy SJ. Lack of correlation of vaginal impedance measurements with hormone levels in the rat. Contemp Top Lab Anim Sci 2005;44: 37-42.

Spicer SS, Lillie RD. Saponification as a means of selectively reversing the methylation blockade of tissue basophilia. J Histochem Cytochem 1959;7: 123-125.

Subramani E, Madogwe E, Ray CD, Dutta SK, Chakravarty B, Bordignon V, Duggavathi R, Chaudhury K. Dysregulated leukemia inhibitory factor and its receptor regulated signal transducers and activators of transcription 3 pathway: a 
possible cause for repeated implantation failure in women with dormant genital tuberculosis? Fertil Steril 2016;105: 1076-1084 e1075.

Weixelbaumer KM, Drechsler S, Wehrenpfennig P, Khadem A, Bahrami S, Tichy A, Palme R, Osuchowski MF. Estrus cycle status defined by vaginal cytology does not correspond to fluctuations of circulating estrogens in female mice. Shock 2014;41: 145-153.

Wilcox AJ, Weinberg CR, O'Connor JF, Baird DD, Schlatterer JP, Canfield RE, Armstrong EG, Nisula BC. Incidence of early loss of pregnancy. $N$ Engl J Med 1988;319: 189-194.

Wood GA, Fata JE, Watson KL, Khokha R. Circulating hormones and estrous stage predict cellular and stromal remodeling in murine uterus. Reproduction 2007;133: 1035-1044.

Zhu Z, Cheng L, Tsui Z, Hakomori S, Fenderson BA. Glycosphingolipids of rabbit endometrium and their changes during pregnancy. J Reprod Fertil 1992;95: 813-823.

Zhu Z, Deng H, Fenderson BA, Nudelman ED, Tsui Z. Glycosphingolipids of human myometrium and endometrium and their changes during the menstrual cycle, pregnancy and ageing. J Reprod Fertil 1990;88: 71-79. 


\section{Figure legends}

Figure 1 A transvaginal probe for measurement of vaginal bioelectrical impedance.

The $3.5 \mathrm{~mm}$ diameter probe with gold-plated two-electrode (1 st electrode; $3 \mathrm{~mm}$ width, interval; $3 \mathrm{~mm}$, 2nd electrode; $1 \mathrm{~mm}$ width).

\section{Figure 2}

Vaginal bioelectrical impedance during the oestrous cycle.

The box plots show vaginal bioelectrical impedance (VZ) in each stage of the oestrous cycle (pro-oestrus; $\mathrm{n}=18$, oestrus; $\mathrm{n}=20$, met-oestrus; $\mathrm{n}=12$, di-oestrus; $\mathrm{n}=13$ ). The horizontal line within the box shows the median, and the dotted line within the box shows the mean value. Represents outliers. The data were evaluated using the Kruskal-Wallis test with Dunn's multiple comparisons $(* P<0.05)$.

\section{Figure 3}

Sulfation and sialylation changes in uterine glycocalyx after the GP3ST+FucT-III transfection.

Alcian blue (A-D) and Maackia amurensis mitogen (MAM) lectin (E-G) staining in uterine tissues 24 hours after gene transfection of GP3ST+FucT-III ( $\beta$ Gal 3-O-sulfotransferase (GP3ST)-alpha (1,3/1,4)fucosyltransferase) (B-D, F-G) or LacZ ( $\beta$-galactosidase, as a control group; A, E). Methylation (G) or combined methylation-saponification $(\mathrm{H})$ pre-treatment before alcian blue staining, or neuraminidase pre-treatment before MAM lectin staining (I) in uterine tissues from the GP3ST+FucT-III group. Lu, lumen; Gl, gland. Scale bars: $100 \mu \mathrm{m}$.

\section{Figure 4}


The effect of sulfation and sialylation changes in uterine glycocalyx on VZ.

The box plots show vaginal impedance 24 hours after gene transfection in the GP3ST and FucT-III-expressing plasmid DNA group (patterned box, $\mathrm{n}=15$ ) and LacZ-expressing plasmid DNA group (gray box, $\mathrm{n}=12$ ). The horizontal line within the box shows the median, and the dotted line within the box shows the mean value. The data were evaluated using the Shapiro-Wilk normality test and Wilcoxon's rank-sum test $(* P<0.05)$.

\section{Figure 5}

Measurement of VZ during the early stages of pregnancy.

The box plots show VZ between day 1.5 and 5.5 post-coitus $(\mathrm{n}=12$ each). The horizontal line within the box shows the median, and the dotted line within the box shows the mean value. The data were evaluated using the Shapiro-Wilk normality test and Student's t-test $(* P<0.005, * * * P<0.05)$ or Wilcoxon's rank-sum test $(* * P<$ $0.001)$.

\section{Figure 6}

The effect of local suppression of Stat3 activity on sulfated and sialylated uterine glycocalyx.

Twenty four hours gene transfection (1 day before implantation began), alcian blue staining with Kernechtrot counterstaining (A-D) and MAM lectin staining with hematoxylin counterstaining (E, F) staining was performed in the uterine tissue with signal transducer and activator of transcription-3 (Stat3) (B, D, F) or scramble (A, C, E) 
569

570

571

572

573

574

575

576

577

578

579

580

581

582

583

584

585

586

587

588

decoy. Lu, lumen; Gl, gland; Ve, blood vessel. Scale bars: (A, B, E, F) 100 m, (C, D) $50 \mu \mathrm{m}$.

\section{Figure 7}

VZ results 1 day before implantation began.

(A) The box plots show the VZ in the scramble decoy-transferred (gray box, $\mathrm{n}=23$ ) and Stat3 decoy-transferred (white box, $\mathrm{n}=21$ ) groups at day 2.5 p.c. The horizontal line within the box shows the median, and the dotted line within the box shows the mean value. The data were evaluated using the Shapiro-Wilk normality test and Wilcoxon's rank-sum test $(* P<0.001)$. (B) The receiver-operating characteristic curve analysis of $\mathrm{VZ}$ as a predictor of non-conception.

Supplementary Figure S1 The effect of the distance from the ostium of the uterus on vaginal bioelectrical impedance.

(A) Schematic position of a transvaginal probe to measure vaginal bioelectrical impedance (VZ). (B) The box plots show the relative VZ value at (i) 5-7 $\mathrm{mm}$ and (ii) more than $7 \mathrm{~mm}$ against $\mathrm{VZ}$ value at (iii) $0-5 \mathrm{~mm}$ from the dead end of the vagina $(\mathrm{n}=$ 40). The horizontal line within the box shows the median, and the dotted line within the box shows the mean value. 
page. $31 / 31$

590 The dotted plots show the number of implantation sites on day 5.0 post-coitus (p.c.) in

591 the scramble decoy (gray dot) and signal transducer and activator of transcription-3

592 (Stat3) decoy (open dot)-transferred groups (A). The data were evaluated using the

593 Shapiro-Wilk normality test and Student's t-test $(* P<0.001)$.

594 The methylation (B) or the combined methylation-saponification (C) pre-treatment

595 before alcian blue staining in uterine tissues from the scramble decoy group. The

596 neuraminidase pre-treatment before Maackia amurensis mitogen (MAM) lectin staining

597 (D, E) in uterine tissues from the scramble (D) and Stat3 (E) decoys group. Lu, lumen;

598 Gl, gland; Ve, blood vessel. Scale bars $=100 \mu \mathrm{m}$.

599 